\title{
Ventriculo-atrial shunt nephritis
}

\author{
MARTIN SEARLE \\ B.SC., B.M., M.R.C.P. \\ H. A. LEE \\ B.Sc., F.R.C.P.
}

Wessex Regional Renal Unit, St Mary's Hospital, Portsmouth

\begin{abstract}
Summary
A case of immune complex glomerulonephritis with reversible renal insufficiency following ventriculoatrial shunting is described and the English language literature is reviewed. The importance of recognizing this reversible glomerulonephritic lesion is emphasized.
\end{abstract}

\section{Introduction}

Infection in the early post-operative period is a common complication of ventriculo-atrial shunting. Renal disease secondary to shunt infection is uncommon and its rather insidious onset may make diagnosis difficult. The syndrome may therefore be relatively under-recognized.

We describe a case which illustrates an unusually acute presentation followed by complete resolution of the disease by appropriate systemic antibiotic therapy, shunt removal and subsequent shunt replacement to an extravascular site.

\section{Case report}

In September 1980 a 38-year-old herdsman was admitted complaining of shortness of breath and haematuria. He gave a 3 week history of malaise, ankle swelling and joint pain. Examination showed fever, generalized oedema, bilateral axillary lymphadenopathy and a petechial rash over both legs. There were bilateral basal crepitations in the chest and the blood pressure was $170 / 100 \mathrm{mmHg}$. Otherwise the cardiovascular system and fundi were normal.

Further questioning revealed that he had had a normal intravenous pyelogram (IVP) and cystoscopy following haematuria in 1978. In August 1979 he had presented with an 18 month history of frontal headaches, dizziness and ataxia and on examination had bilateral papilloedema. A computed tomographic (CT) scan revealed an aqueduct stenosis, no cause for which was found at pneumoencephalography. A Spitz-Holter ventriculo-atrial shunt was inserted and he made a full recovery and returned to work.
Investigations showed a normochromic, normocytic anaemia, haemoglobin $8.8 \mathrm{~g} / \mathrm{dl}$, total and differential white cell count and platelet count were normal. The erythrocyte sedimentation rate (ESR) was $110 \mathrm{~mm} / \mathrm{hr}$. The blood urea was $16.8 \mathrm{mmol} / \mathrm{l}$, creatinine $214 \mu \mathrm{mol} / 1$, albumin $27 \mathrm{~g} / \mathrm{l}$, alkaline phosphatase $170 \mathrm{iu} . / 1$ (normal 30-95) with normal serum electrolytes, calcium and liver function tests. Urine microscopy showed greater than 10 red cells/high power field and a few granular casts. Total urinary protein excretion was $0.7 \mathrm{~g}$ in $24 \mathrm{hr}$. An IVP demonstrated enlarged kidneys each of $18 \mathrm{~cm}$ in length. Attempted renal biopsy under ultrasound control was unsuccessful.

Treatment was started with an $80 \mathrm{~g}$ protein, 6 mmol sodium daily diet and a 2 litre fluid allowance Frusemide $250 \mathrm{mg}$ daily was started.

Twelve days after admission intermittent fever continued with rigors but no cardiac murmurs were heard. Blood cultures repeatedly grew Staphylococcus albus. The ESR remained elevated and serum complement fractions were low with a C3 0.34 $\mathrm{g} / 1$ (normal $0.5-0.9$ ) and a C4 0.09 g/1 (normal $0 \cdot 2-0 \cdot 6$ ). Serial chest $X$-rays showed transient areas of consolidation (Fig. 1). A working diagnosis of shunt nephritis was made and, after an unsuccessful attempt at aspirating cerebrospinal fluid from the shunt chamber, treatment with flucloxacillin $1 \mathrm{~g}$ three times daily and fusidic acid $1 \mathrm{~g}$ three times daily was started.

He was transferred to the Wessex Neurological Centre for shunt removal after which his neurological status deteriorated requiring a temporary ventricular drain and later a permanent ventriculo-pleural shunt. Cephradine $500 \mathrm{mg}$ four times daily was substituted for the above antibiotics. $S$. albus was isolated from the shunt system.

An open renal biopsy performed at the time of shunt removal showed diffuse proliferative glomerulonephritis with $20 \%$ crescents (Fig. 2). Immunofluorescence studies showed granular deposits of IgM and $\mathrm{C} 3$ in the glomerular basement membrane and also linear fibrinogen and albumin deposits in the tubular and glomerular membranes. Electron micro- 


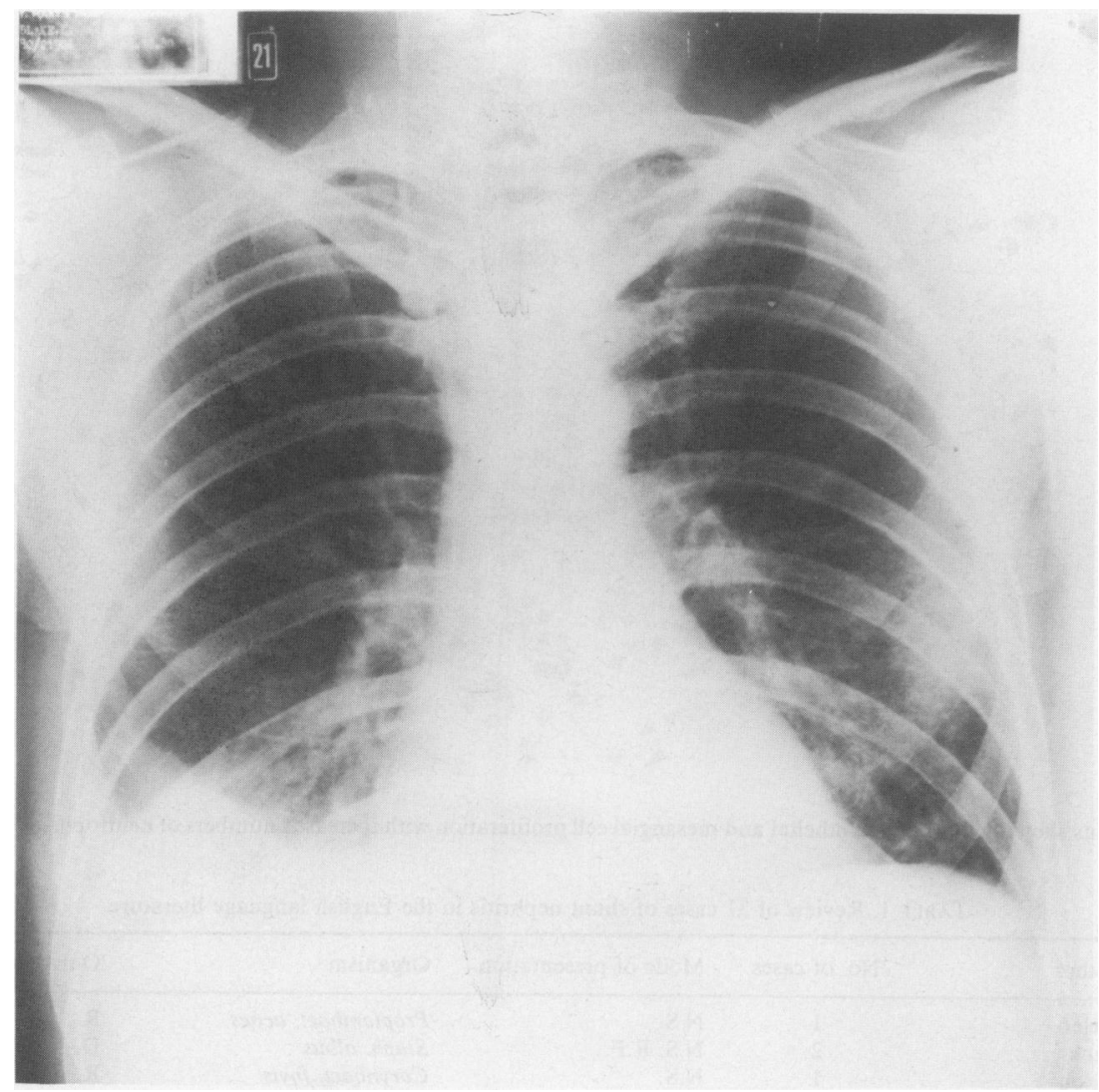

FIG. 1. Chest X-ray day 12 showing ventriculo-atrial shunt and consolidation at right base and left mid zone.

scopy showed $50 \%$ crescents and some epithelial electron dense deposits.

Treatment lead to the resolution of his clinical signs and proteinuria within 8 weeks. Renal function, ESR, complement fractions and chest $\mathrm{X}$-ray returned to normal within this time at the end of which he was discharged and he was able to return to work 4 weeks later.

\section{Discussion}

Black, Challacombe and Ockenden (1965) reported the first description of two cases of the nephrotic syndrome associated with chronic shunt infection with $S$. albus. Since then a further 29 well documented cases of shunt nephritis have been described in the literature and others referred to in less detail at various meetings (Hanson, 1964; Holland, 1967; Northway, 1969; Leumann, 1971).

The incidence of shunt infection is said to be around 14\% (Shurtleff, Christie and Foltz, 1971) and $S$. albus is responsible in over $50 \%$ of cases; other organisms found are $S$. aureus and Gram negative bacteria (Schoenbaum, Gardner and Shillito, 1975).
Only a few of these infections became chronic and resulted in irreversible renal disease; most infections were immediately postoperative.

Shunt infection is usually manifested by the cardinal signs of fever, malaise, raised ESR and hepatosplenomegaly. Proteinuria, haematuria and the nephrotic syndrome indicate renal involvement. Our case was notable for his acute presentation.

The usually insidious onset of secondary renal disease means that the diagnosis may be missed or delayed (McKenzie and Hayden, 1974; Finney and Roberts, 1980) by failure to look for proteinuria in neuro-surgical clinics, by negative blood cultures, or by misinterpretation of $S$. albus grown in the blood as a contaminant. In this respect it is essential to culture shunt fluid if the diagnosis is suspected. Anaerobic cultures may also be necessary (Beeler et al., 1976).

Renal biopsy will usually show a proliferative glomerulonephritis, sometimes with crescent formation. Immunofluorescence studies have shown subendothelial deposits of C3, C4 and IgM. S. albus antigen has been demonstrated in the biopsy specimens and in circulating cryoglobulins (Dobrin et al., 1975) which have been shown to contain immune 


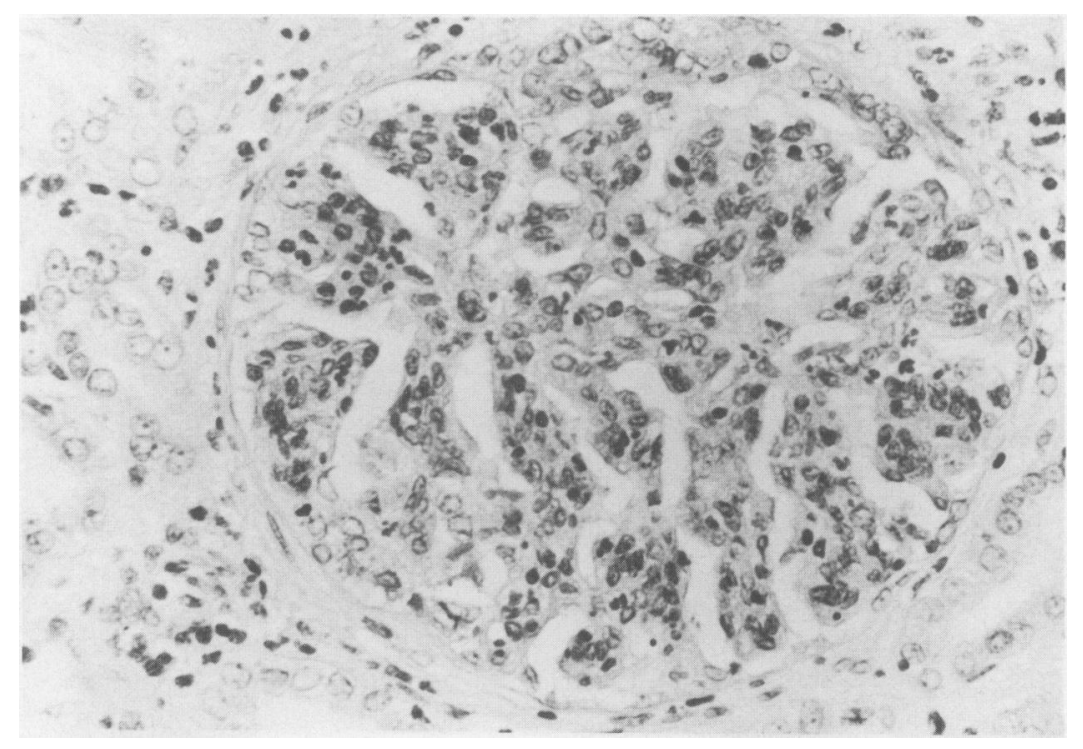

FIG. 2. Glomerulus showing marked endothelial and mesangial cell proliferation with increased numbers of neutrophil polymorphs. HE $\times 350 \Omega$

TABLE 1. Review of 31 cases of shunt nephritis in the English language literature

\begin{tabular}{lclll}
\hline Author & No. of cases & Mode of presentation & Organism & Outcome \\
\hline Beeler & 1 & N.S. & Propionibact. acnes & R. \\
Black & 2 & N.S. R.F. & Staph. albus & D. \\
Bolton & 1 & N.S. & Corynbact. fovis & R. \\
Dobrin & 3 & H. & Staph. albus & R. \\
Finney & 4 & H. R.F. (3) P. & Staph. albus (3) & R. \\
& & & Propionibact. acnes (1) & R. \\
Kaufmann & 1 & H. R.F. & Staph. albus & D. \\
Lam & 1 & N.S. & Staph. albus & D. \\
McKenzie & 2 & N.S. R.F.+ H. & Staph. albus & R. D. \\
Moncrieff & 1 & N.S. & Staph. albus & R. \\
Rames & 3 & H. (2) N.S. & Staph. albus & R. (2) D. \\
Rodriques-Gironies & 1 & N.S. & Pseudomonas aeruginosa & N.G. \\
Searle & 1 & H. & Staph. albus & R. \\
Stickler & 6 & N.S. (5) P. & Staph. albus (5) & R. (3) \\
Strife & & & Staph. aureus (1) & D. (3) \\
& 4 & H. & Staph. albus (3) & N.G. \\
\hline
\end{tabular}

$\begin{array}{ll}\text { KEY: N.S. = Nephrotic syndrome } & \text { R. = Full recovery } \\ \text { R.F. }=\text { Renal failure } & \text { D. = Died } \\ \text { H. }=\text { Haematuria } & \text { N.G. = Not given } \\ \text { P. }=\text { Proteinuria } & \end{array}$

complexes (Strife et al., 1976). Circulating complement components are reduced, activation has been shown to be via the classic pathway, and positive rheumatoid factor tests have been found (Dobrin $e t$ al., 1975) and in this respect the disease resembles lupus nephritis. From Table 1 it can be seen that the presenting renal manifestation in 31 cases was the nephrotic syndrome in 13 , with various degrees of renal insufficiency in 6, macroscopic haematuria in 11 and proteinuria in 2 . Of the 31 cases the outcome was a full recovery in 17,9 died and in the remaining 5 the eventual outcome was not known. In $25(81 \%)$ o cases $S$. albus was the causative organism.

Complications of shunt nephritis may include renal failure which is usually reversible with prompt and appropriate treatment but if not recognized early or treated appropriately may be fatal (McKenzie and $\stackrel{\circ}{=}$

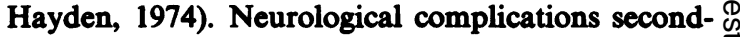
ary to temporary shunt removal, as seen in this case, may cause serious problems and indeed most of the 
deaths recorded were associated with such complications. Embolization from the infected shunt system may produce pulmonary complications (Emery \& Hilton, 1961) as seen in this case. Treatment must be appropriate with systemic antibiotics and removal of the shunt system (Sells, Shurtleff and Loesser, 1977). Temporary ventricular drainage may be necessary and it is important that later re-insertion of a permanent shunt system is made into an extravascular site (Black et al., 1965; Shurtleff et al., 1974; Finney and Roberts, 1980).

\section{Acknowledgments}

We would like to thank Dr Clair du Boulay, Lecturer in Histopathology at Southampton University Medical School, Mr Jason Brice, Consultant Neurosurgeon and Mr Jonathan Punt, Senior Registrar in Neurosurgery, Wessex Neurological Centre, Southampton General Hospital, for their assistance in the management of this case.

\section{References}

Beeler, B. A., Crowder, J. G., SMith, J. W. \& White, A. (1976) Proprionibacterium acnes: pathogen in central nervous system shunt infection. Report of 3 cases including immune complex glomerulonephritis. American Journal of Medicine, 6, 935.

Black, J. A., Challacombe, D. N. \& OCKenden, B. G. (1965) Nephrotic syndrome associated with bacteraemia after shunt operations for hydrocephalus. Lancet, if, 921.

Bolton, W. K., SANDe, M. A., Normansel, D. E., Sturgill, B. C. \& WESTERVALT, F. B. (1975) Ventriculojugular shunt nephritis with Cornebactrium bovis. Successful therapy with antibiotics. American Journal of Medicine, 59, 417.

Dobrin, R. S., DAY, N. K., QUIE, P. G., MOORE, H. L., Vernier, R. L., MICHAel, A. F. \& FiSH, A. J. (1975) The role of complement immunoglobulin and bacterial antigen in coagulase-negative staphylococcal shunt nephritis. American Journal of Medicine, 59, 660.

EMERY, J. L. \& HILTON, H. B. (1961) Lung and heart complications of the treatment of hydrocephalus by ventriculoauriculostomy. Surgery (St. Louis), 50, 309.

FINNEY, H. L. \& ROBERTS, T. S. (1980) Nephritis secondary to chronic cerebrospinal fluid-vascular shunt infection: 'Shunt Nephritis'. Child's Brain, 6, 189.
Hanson, M. F. (1964) Case Report 35th Annual meeting of The Society of Pediatric Research, Philadelphia May 4th.

Holland, N. (1967) Case Report of the 37th Annual meeting of the Society of Pediatric Research, Philadelphia April 28th.

KAUfMAN, D. B. \& McINTOSH, R. (1971) The pathogenesis of the renal lesion in a patient with streptococcal infection of a ventricular atrial shunt, cryoglobulin anaemia and nephritis. American Journal of Medicine, 50, 262.

LAM, C. N., MCNEISH, A. S. \& GiBSON, A. A. M. (1969) Nephrotic syndrome associated with complement deficiency and Staph. albus bacteraemia. Scottish Medical Journal, 14, 86.

Leumann, E. P. (1971) Case Report: Proceedings of the second symposium of International Nephrologie Pediatrique (Paris), 166.

MCKENzIE, S. A. \& HAYDEN, K. (1974) Two cases of shunt nephritis. Pediatrics, 54, 806.

MonCriefF, M. W., Glasgow, E. F., ARThUR, L. J. H. \& HARGREAVES, H. M. (1973) Glomerulonephritis associated with Staph. albus in a Spitz-Holter valve. Annals of Diseases of Childhood, 54, 69.

Northway, J. D. (1969) Case Report: The North Pacific Pediatric Society, Portland, Oregan, March 5th.

Rames, L., Wise, B., Goodman, J. R. \& Piel, F: (1970) Renal disease with Staph. albus bacteraemia. Journal of the American Medical Association, 212, 1671.

RODRIQUES- GIRONIES, M. \& GeNOVES, A. (1977) Bacteraemia by Pseudomonas aeruginosa with nephrotic syndrome after shunt operation for hydrocephalus. Chemotherapy, 23, Suppl. 1, 423.

SCHOENBAUM, S. C., GARDNER, P. \& ShILlito, J. (1975) Infections of C.S.F. shunts: epidemiology, clinical manifestations and therapy. Journal of Infectious Diseases, 5, 543.

SELLS, C. J., SHURTLEFF, D. B. \& LOESSER, J. (1977) Gram negative C.S.F. shunt associated infection. Pediatrics, 59, 614.

ShurtlefF, D. B., Christie, D. V. \& Foltz, E. L. (1971) Ventriculoauriculostomy-associated infection-a 12 year study. Journal of Neurosurgery, 35, 686.

SHURTLEFF, D. B., FolTZ, E. L., WeEKS, R. D. \& LoESSER, J. (1974) Therapy of Staphylococcus epidermis infection associated with C.S.F. shunt. Pediatrics, 1, 55.

Stickler, G. B., Shin, M. H., Burke, E. C., Holley, K. E., MILLER, R. H. \& SEGAR, W. E. (1968) Diffuse glomerulonephritis associated with infected ventriculo-atrial shunt. New England Journal of Medicine, 279, 1077.

STRIFE, C. F., MCDONALd, B. M., RULeY, E. J., MCADams, A. J. \& WEST, C. D. (1976) Shunt nephritis: The nature of the serum cryoglobulins and their relation to the complement profile. Journal of Pediatrics, 3, 403. 